\title{
Varying Auxin Levels Induce Distinct Pluripotent States in Callus Cells
}

\author{
Jinwoo Shin ${ }^{1+}$ and Pil Joon Seo ${ }^{1,2,3 *}$ \\ ${ }^{1}$ Department of Biological Sciences, Sungkyunkwan University, Suwon, South Korea, ${ }^{2}$ Department of Chemistry, Seoul \\ National University, Seoul, South Korea, ${ }^{3}$ Plant Genomics and Breeding Institute, Seoul National University, Seoul, South \\ Korea
}

Keywords: auxin, callus, cellular reprogramming, cytokinin, plant regeneration, pluripotency

\section{OPEN ACCESS}

Edited by:

Patrick H. Masson,

University of Wisconsin-Madison,

United States

Reviewed by:

Feng Ning Xiang,

Shandong University, China

G. Eric Schaller,

Dartmouth College, United States

*Correspondence:

Pil Joon Seo

pjseo1@snu.ac.kr

${ }^{\dagger}$ Present Address: Department of Molecular Biology and Centre for Computational and Integrative Biology,

Massachusetts General Hospital, and Department of Genetics, Harvard Medical School, Boston, MA,

United States

Specialty section:

This article was submitted to Plant Physiology,

a section of the journal

Frontiers in Plant Science

Received: 17 July 2018 Accepted: 24 October 2018 Published: 13 November 2018

Citation:

Shin J and Seo PJ (2018) Varying Auxin Levels Induce Distinct Pluripotent States in Callus Cells.

Front. Plant Sci. 9:1653.

doi: 10.3389/fp/s.2018.01653
Plants have evolved a remarkable ability for reprogramming cell identity to facilitate tissue repair and developmental plasticity. During cell fate transition, an unorganized pluripotent cell mass, called a callus, is formed. Two major types of calli are observed depending on the inductive external stimuli: mechanical wounding alone or wounding followed by incubation on high auxin-containing callus-inducing medium (CIM) (Ikeuchi et al., 2013). Wound-induced calli and CIM-induced calli are similar in having pluripotency that ensures competence for subsequent tissue regeneration. However, the identity of pluripotency in wound-induced calli and CIM-induced calli is not analogous.

Wound-induced calli derive from various cell types and regenerate new tissues. Mechanical wounding without exogenous auxin treatment primarily activates cytokinin signaling and induces minimal callus cells at excised regions (Iwase et al., 2011). An AP2/ERF transcription factor, WOUND-INDUCED DEDIFFERENTIATION 1 (WIND1), and its close homologs, WIND2, WIND3, and WIND4, are central regulators of wound-induced callus formation in Arabidopsis (Iwase et al., 2011). Dominant-negative repression of WINDs, WIND1-SRDX, results in reduced callus formation in hypocotyl explants (Iwase et al., 2011), whereas overexpression of individual WIND genes is sufficient to induce calli from somatic cells (Iwase et al., 2011). The WIND proteins act through type-B ARABIDOPSIS RESPONSE REGULATORs (ARRs), which are key components of cytokinin signaling, and consistently, WIND activation of callus formation is strongly repressed in $\operatorname{arr} 1$ arr12 double mutants (Iwase et al., 2011).

Upon endogenous activation of cytokinin signaling, concomitant with basal auxin biosynthetic activity, cell fate can be reversibly and freely switched. A low barrier of cell fate changes may lead to the coexistence of bipotent stem cells in callus tissues, which can give rise to either a root or shoot fate. This intermediate phase allows flexible tissue regeneration depending on the adjacent cells. Indeed, wound-induced calli are optimized for tissue repair. Neighboring cells, which are in direct contact with damaged regions, rapidly activate the ETHYLENE RESPONSE FACTOR 115 (ERF115)-PHYTOCHROME A SIGNAL TRANSDUCTION 1 (PAT1) complex to replenish collapsed cells through active reentry into the cell cycle. The ERF115-PAT1 complex possibly promotes WIND1 expression by directly binding to the gene promoter (Heyman et al., 2016). WIND1 further regulates cytokinin-dependent cell division and tissue regeneration (Iwase et al., 2017), facilitating rapid damage healing (Figure 1). Despite a high efficiency of tissue repair, WIND1-overexpressing calli show reduced ability of de novo organogenesis without incubation on CIM (Iwase et al., 2017), reinforcing the optimized role of wound-induced calli in tissue repair.

High concentrations of auxin, in addition to mechanical wounding, result in another level of cell fate changes. Unlike wound-induced calli that do not display particular tissue identity, 
CIM-induced calli are similar to root primordium irrespective of the origin of the explants (Atta et al., 2009; Sugimoto et al., 2010). Although the calli are not genuine root primordia themselves, the calli have a gene expression profile similar to that found in root primordia and a genetic circuit of callus formation and root primordium establishment is significantly overlapped. On CIM, a pluripotent callus is usually induced from pericycle cells (or pericycle-like cells of aerial tissues) adjacent to the xylem poles though asymmetric or formative divisions (Valvekens et al., 1988; Atta et al., 2009), similar to lateral root emergence. Consistently, auxin signaling components mediating lateral root initiation are also involved in CIMinduced callus formation. The ARABIDOPSIS TRITHORAXRELATED 2 (ATXR2)-AUXIN RESPONSE FACTOR (ARF)LATERAL ORGAN BOUNDARIES DOMAIN (LBD) axis is a crucial signaling scheme underlying lateral root formation as well as callus formation (Okushima et al., 2007; Fan et al., 2012; Lee et al., 2017). ATXR2 interacts with ARF7 and ARF19, and the ATXR2-ARF complex specifically binds to the LBD16 and $L B D 29$ promoters and activates expression through deposition of the active H3K36me3 mark, stimulating proliferation of pericycle competent cells and conferring root primordium characteristics in the callus (Okushima et al., 2007; Lee et al., 2017) (Figure 1). Accordingly, CIM-induced callus formation is impaired in leaf explants of atxr2 and arf7arf19 mutants and LBD-SRDX transgenic plants (Fan et al., 2012; Lee et al., 2017).

Following acquisition of root primordium characteristics in calli, many root stem cell regulators including WUSCHELRELATED HOMEOBOX 5 (WOX5), SCARECROW (SCR), PLETHORA 1 (PLT1), and PLT2 are expressed in callus cells (Atta et al., 2009; Kareem et al., 2015), although they have relatively broad spatial expression in the callus, rather than a confined expression into specific cell types. The histone acetyltransferase HISTONE ACETYLTRANSFERASE OF THE GNAT FAMILY 1 (HAG1)/ GENERAL CONTROL NONDEREPRESSIBLE 5 (GCN5) transcriptionally activates root-meristem genes in calli, including WOX5, WOX14, SCR, PLT1, and PLT2, establishing competence for subsequent de novo organogenesis (Kim et al., 2018). In addition, miRNA-directed ARF regulation is also involved in this process. The miR160 represses pluripotency acquisition during callus formation through mRNA cleavage of $A R F 10$, which controls differentiation of distal root stem cells by defining spatial expression patterns of root stem cell regulators, such as WOX5 and PLTs, as well as a cytokinin signaling gene ARABIDOPSIS RESPONSE REGULATOR 15 (ARR15) (Ding and Friml, 2010; Liu et al., 2016). Moreover, the LBD-bZIP59 complex further directly regulates the $F A D$-binding Berberine $(F A D-B D)$ gene to facilitate pluripotency establishment in calli (Xu et al., 2018). Cell clustering that has similarity to the root stem cell niche may be the identity of pluripotency in CIM-induced calli, ensuring competence for de novo organogenesis (Liu et al., 2018a).

Consistent with the fact that callus tissues have similarity to root primordium, de novo root organogenesis can spontaneously occur from callus cells especially at a lower concentration of exogenous auxin (Yu et al., 2017). In support, significant

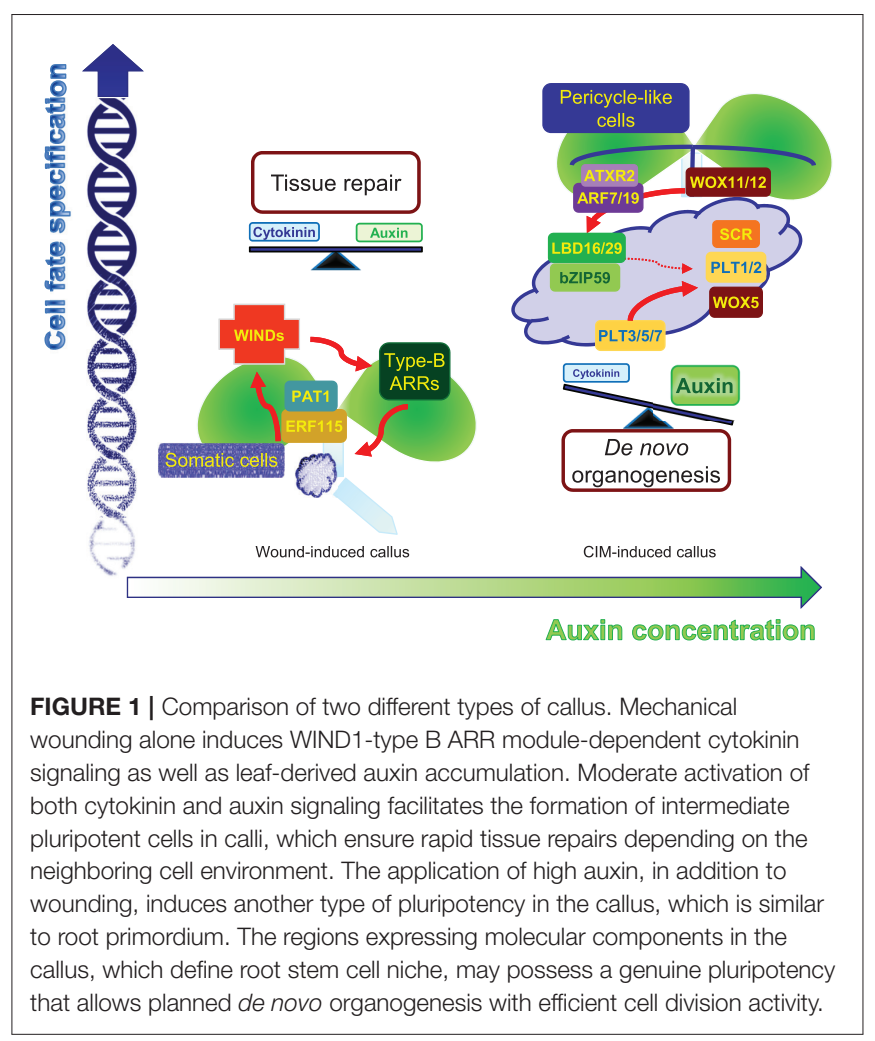

overlap of molecular components between de novo root organogenesis and callus formation have been demonstrated (Liu et al., 2014, 2018b; Lee et al., 2018). Notably, de novo shoot organogenesis can also be derived from CIM-induced calli. Since molecular components and networks in the stem cell niche of the shoot and root are well conserved (Sarkar et al., 2007; Rosspopoff et al., 2017), callus cells expressing root meristem regulators may be efficiently converted into shoot meristem upon incubation on shoot-inducing medium (SIM). Consistently, lbd16 single and plt3/5/7 triple mutants, which impair root meristem specification, show an inability for not only root organogenesis but also shoot regeneration from CIM-induced calli (Kareem et al., 2015). In addition, this type of pluripotency facilitates stepwise de novo organogenesis during in vitro plant regeneration. Upon transfer of calli preincubated on CIM to SIM, transcript levels of root stem cell regulators promptly decline. However, it is noteworthy that shoot stem cell regulators, WUSCHEL (WUS) and SHOOT MERISTEMLESS (STM), are slowly induced, rather than being rapidly activated, in a confined domain in response to high cytokinin (Gordon et al., 2007). A clear lag phase is established between the peak expression of root and shoot stem cell regulators, and this phase prevents reversible cell fate switching, directing planned tissue regeneration.

A remaining question would be what characteristics of the root primordium-like tissues are advantageous to calli for pluripotency. Accumulating evidence has suggested that the 
root primordium has an efficient cell proliferation system. Callus cells originate from the pericycle cells, which have low endoreduplication activity and thereby active cell division (Blakely and Evans, 1979). Endoreduplicated cells with high DNA contents have reduced regenerative potential and low genome integrity (Torrey, 1967). In support, CIM-induced calli, which begin with pericycle cells, ensure not only division activity but also genome integrity, while wound-induced calli allow high frequency regeneration of polyploid shoots (Torrey, 1967). Moreover, photosynthetic activity most likely interferes with pluripotent callus formation. Extensive light reactions require expensive reactive oxygen species (ROS) scavenging systems to deal with excessive endogenous free radicals. Given the trade-off between ROS metabolism and cell proliferation, plants have likely evolved to undergo transition into the root meristem during callus formation to enable active cell division.

Overall, unlike wounding alone, high auxin plus wounding provides limited flexibility of cell fate transition and thereby ensures stepwise transition of cell identity. This facilitates planned de novo organogenesis, which is required for the in vitro

\section{REFERENCES}

Atta, R., Laurens, L., Boucheron-Dubuisson, E., Guivarc'h, A., Carnero, E., Giraudat-Pautot, V., et al. (2009). Pluripotency of Arabidopsis xylem pericycle underlies shoot regeneration from root and hypocotyl explants grown in vitro. Plant J. 57, 626-644. doi: 10.1111/j.1365-313X.2008.03 715.x

Blakely, L. M., and Evans, T. A. (1979). Cell dynamics studies on the pericycle of radish seedling roots. Plant Sci. Lett. 14, 79-83. doi: 10.1016/0304-4211(79)90158-5

Ding, Z., and Friml, J. (2010). Auxin regulates distal stem cell differentiation in Arabidopsis roots. Proc. Natl. Acad. Sci. U.S.A. 107, 12046-12051. doi: $10.1073 /$ pnas. 1000672107

Fan, M., Xu, C., Xu, K., and Hu, Y. (2012). LATERAL ORGAN BOUNDARIES DOMAIN transcription factors direct callus formation in Arabidopsis regeneration. Cell Res. 22, 1169-1180. doi: 10.1038/cr.2012.63

Gordon, S. P., Heisler, M. G., Reddy, G. V., Ohno, C., Das, P., and Meyerowitz, E. M. (2007). Pattern formation during de novo assembly of the Arabidopsis shoot meristem. Development 134, 3539-3548. doi: 10.1242/dev.0 10298

Heyman, J., Cools, T., Canher, B., Shavialenka, S., Traas, J., Vercauteren, I., et al. (2016). The heterodimeric transcription factor complex ERF115-PAT1 grants regeneration competence. Nat. Plant 2:16165. doi: 10.1038/nplants.2016.165

Ikeuchi, M., Sugimoto, K., and Iwase, A. (2013). Plant callus: mechanisms of induction and repression. Plant Cell 25, 3159-3173. doi: 10.1105/tpc.113.116053

Iwase, A., Harashima, H., Ikeuchi, M., Rymen, B., Ohnuma, M., Komaki, S., et al. (2017). WIND1 promotes shoot regeneration through transcriptional activation of ENHANCER OF SHOOT REGENERATION1 in Arabidopsis. Plant Cell 29, 54-69. doi: 10.1105/tpc.16.00623

Iwase, A., Mitsuda, N., Koyama, T., Hiratsu, K., Kojima, M., Arai, T., et al. (2011). The AP2/ERF transcription factor WIND1 controls cell dedifferentiation in Arabidopsis. Curr. Biol. 21, 508-514. doi: 10.1016/j.cub.2011. 02.020

Kareem, A., Durgaprasad, K., Sugimoto, K., Du, Y., Pulianmackal, A. J., Trivedi, Z. B., et al. (2015). PLETHORA genes control regeneration by a two-step mechanism. Curr. Biol. 25, 1017-1030. doi: 10.1016/j.cub.2015. 02.022

Kim, J. Y., Yang, W., Forner, J., Lohmann, J. U., Noh, B., and Noh, Y. S. (2018). Epigenetic reprogramming by histone acetyltransferase HAG1/AtGCN5 is tissue culture process. This type of pluripotency, which resembles the root primordium, possesses a genuine competence for tissue regeneration with a cost-effective cell division process.

\section{AUTHOR CONTRIBUTIONS}

All authors listed have made a substantial, direct and intellectual contribution to the work, and approved it for publication.

\section{FUNDING}

This work was supported by the Basic Science Research (NRF-2016R1D1A1B03931139) and Basic Research Laboratory (NRF-2017R1A4A1015620) programs provided by the National Research Foundation of Korea and by the Next-Generation BioGreen 21 Program (PJ01319304) provided by the Rural Development Administration.

\section{ACKNOWLEDGMENTS}

We thank Dr. M. S. Choi for her comments on our paper. required for pluripotency acquisition in Arabidopsis. EMBO J. 37:e98726. doi: 10.15252/embj.201798726

Lee, K., Park, O. S., and Seo, P. J. (2017). Arabidopsis ATXR2 deposits H3K36me3 at the promoters of $L B D$ genes to facilitate cellular dedifferentiation. Sci. Signal. 10:eaan0316. doi: 10.1126/scisignal.aan0316

Lee, K., Park, O. S., and Seo, P. J. (2018). ATXR2 as a core regulator of de novo root organogenesis. Plant Signal. Behav. 13:e1449543. doi: 10.1080/15592324.2018.1449543

Liu, J., Hu, X., Qin, P., Prasad, K., Hu, Y., and Xu, L. (2018a). The WOX11LBD16 pathway promotes pluripotency acquisition in callus cells during de novo shoot regeneration in tissue culture. Plant Cell Physiol. 59, 734-743. doi: 10.1093/pcp/pcy010

Liu, J., Sheng, L., Xu, Y., Li, J., Yang, Z., Huang, H., et al. (2014). WOX11 and 12 are involved in the first-step cell fate transition during de novo root organogenesis in Arabidopsis. Plant Cell 26, 1081-1093. doi: 10.1105/tpc.114. 122887

Liu, W., Yu, J., Ge, Y., Qin, P., and Xu, L. (2018b). Pivotal role of LBD16 in root and root-like organ initiation. Cell. Mol. Life Sci. 75, 3329-3338. doi: 10.1007/s00018-018-2861-5

Liu, Z., Li, J., Wang, L., Li, Q., Lu, Q., Yu, Y., et al. (2016). Repression of callus initiation by the miRNA-directed interaction of auxin-cytokinin in Arabidopsis thaliana. Plant J. 87, 391-402. doi: 10.1111/tpj.13211

Okushima, Y., Fukaki, H., Onoda, M., Theologis, A., and Tasaka, M. (2007). ARF7 and ARF19 regulate lateral root formation via direct activation of LBD/ASL genes in Arabidopsis. Plant Cell 19, 118-130. doi: 10.1105/tpc.106. 047761

Rosspopoff, O., Chelysheva, L., Saffar, J., Lecorgne, L., Gey, D., Caillieux, E., et al. (2017). Direct conversion of root primordium into shoot meristem relies on timing of stem cell niche development. Development 144, 1187-1200. doi: 10.1242/dev.142570

Sarkar, A. K., Luijten, M., Miyashima, S., Lenhard, M., Hashimoto, T., Nakajima, K., et al. (2007). Conserved factors regulate signalling in Arabidopsis thaliana shoot and root stem cell organizers. Nature 446:811. doi: 10.1038/nature 05703

Sugimoto, K., Jiao, Y., and Meyerowitz, E. M. (2010). Arabidopsis regeneration from multiple tissues occurs via a root development pathway. Dev. Cell 18, 463-471. doi: 10.1016/j.devcel.2010.02.004

Torrey, J. G. (1967). Morphogenesis in relation to chromosomal constitution in long-term plant tissue cultures. Physiol. Plant. 20, 265-275. doi: 10.1111/j.1399-3054.1967.tb07162.x 
Valvekens, D., Van Montagu, M., and Van Lijsebettens, M. (1988). Agrobacterium tumefaciens-mediated transformation of Arabidopsis thaliana root explants by using kanamycin selection. Proc. Natl. Acad. Sci. U.S.A. 85, 5536-5540. doi: $10.1073 /$ pnas.85.15.5536

Xu, C., Cao, H., Zhang, Q., Wang, H., Xin, W., Xu, E., et al. (2018). Control of auxin-induced callus formation by bZIP59-LBD complex in Arabidopsis regeneration. Nat. Plant 4, 108-115. doi: 10.1038/s41477-017-0095-4

Yu, J., Liu, W., Liu, J., Qin, P., and Xu, L. (2017). Auxin control of root organogenesis from callus in tissue culture. Front. Plant Sci. 8:1385. doi: $10.3389 /$ fpls.2017.01385
Conflict of Interest Statement: The authors declare that the research was conducted in the absence of any commercial or financial relationships that could be construed as a potential conflict of interest.

Copyright (C) 2018 Shin and Seo. This is an open-access article distributed under the terms of the Creative Commons Attribution License (CC BY). The use, distribution or reproduction in other forums is permitted, provided the original author $(s)$ and the copyright owner(s) are credited and that the original publication in this journal is cited, in accordance with accepted academic practice. No use, distribution or reproduction is permitted which does not comply with these terms. 